\title{
Central Bank Behavior and Credibility: Some Recent Theoretical Developments
}

\author{
Alex Cukierman
}

NE of the most widely accepted tenets of monetary theory is that persistent inflation is a monetary phenomenon. A deeper understanding of persistent inflation, therefore, must uncover the reasons for persistent increases in the money stock. This leads naturally to an investigation of the motives and constraints facing central bankers who decide the course of monetary policy.

Recent theoretical literature on the behavior of monetary policymakers may be divided into two broad categories - positive and normative. The positive literature formulates hypotheses about the objectives and constraints facing central bankers and derives implications for the behavior of both observable variables leg., the rate of monetary growth and the rate of inflation) and unobservable variables le.g., policy credibility). The normative literature focuses on the issue of how, given the behavior of central bankers, monetary institutions can be redesigned to improve social welfare. Both approaches use the same general analytic framework to model central bank behavior.

This paper, the first in a two-part survey, focuses on the posilive aspecis of central bank behavior, with particular emphasis on the characterization and the deferminants of policy credibility.

Alex Gukieman is a professor of economics at Tel-Aviv University and a former visiting scholar at the Federal Reserve Bank of St. Louis. David d. Flanagan provided research assistance.

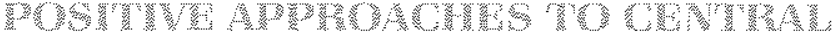

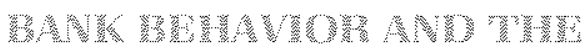

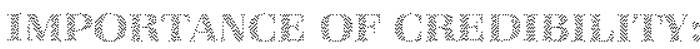

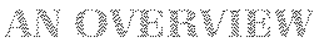

Positive (and normative) theories of central bank behavior rely heavily on the notion that unanticipated money growth has temporary, positive effects on out put and employment as a result either of the Lucas (1973) effect ${ }^{3}$ of the existence of long-term contracts in conjunction with ex post determination of employment by labor demand. ' They also rely on the view that central bankers have a well-defined objective function (preferences) for economic stimulation and inflation within each period as well as intertemporal preferences over combinations of those variables in the present and in the fiture.

The notion of policy credibility is a fundamental one because the ability of monetary policymakens to achieve their future objectives depends on the inflationary expectations of the public. These inlationary expectations depend, in tum, on the public's evaluation of the credibility of the monetary policymakens. For example, Felner (1976) and Haberter 1980, who coired the term "Credibility Hypothesis," have stressed that the less credible disinflationary policies are, the longer and the more severe their interim adverse economic effects will be.

${ }^{1}$ A recent exposition appears in chapter 3 of Cukieman (1984).

2\%ischer (1977), Taylor (1980). 
The theoretical literature defines credibility as the extent to which the public believes that a shift in policy has taken place when, indeed, such a shift has actually occurred." More important, to be credible, a policy must be consistent, at each stage, whithe public's information about the objectives and constraints facing the central bank. The public will not believe an announced policy if it knows the policy is incompatible with the current objectives of policymakers.

Part of the theoretical literature interprets the central bank's objective function as a social welfare function. In this approach, the policymaker is cast as a benevolent planner whose sole concern is to maximize a well-defined social welfare function. Arother part of the literature interprets the objective function of the policymaker in terms of political objectives. In this approach, the importance assigned to preventing inflation relative to stimulating the economy depends on the relative influence on the central bank of the pro-stimulation and anti-inflation advocates within government and the private sector. Formal models based on the social welfare and political approaches are similar at times; however, interpretations of their results are quite different depending on which approach is used. Therefore, the two approaches are discussed separately.

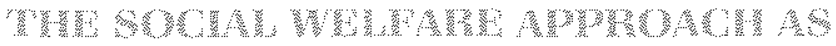

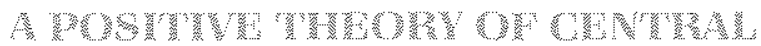

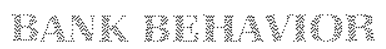

The social welfare approach is based on thee key relationships. First, the economy is one in which deviations of employment from its natural level are positively related to unanticipated inflation; this can result from either the existence of a lucas (1973)-type shortun phillips curve or a Fischer (1977)-Taylor (1980) contract framework. Second, the monetary authority has a social welfare function that gives a negative weight to inflation and a positive weight to employment even beyond the natumal rate. II chooses the rate of money growth and, hence, inflation, over which it has perfect contol, that maximizes the social

\footnotetext{
Under this defintion, a new policy is credible if it is promplly believed, whether or not the new policy is more or less intlationary than the old one. This point is made in a related survey by McCallum (1984).

"The natural rate is the level of employment that would be obtained in the absence of monetary disturbances. Employment or output beyond this level contributes lo social welfare if distortionary taxes or oher constraints hold employment below its optimal level. An elaboration appears at the end of this section.
}

\section{Table 1}

\section{The Monetary Policy Game: Basic Model}

\section{Output Relationship}

(1) $y=y_{n}+\left(m-m^{n}\right)$

II. Social Welfare Function $=$ Policymaker's Objective Function

(2) $w=-m^{2}+2\left(y-y_{n}\right)$

HI. Policymaker's Objective Function in terms of $\mathrm{m}$

(3) $W=-m^{2}+2\left(m-m^{n}\right)$

V. Public s Utility function

(4) $\mathrm{U}=-(\mathrm{m}-\mathrm{m}))^{2}$

welfare hunction. Finally, the public understands the central bank's behavior and forms its inflationary expectations accordingly. Since inflation is "bad," the best mate of monetary expansion must be zero. Therefore, social welfare is maximized when both the actual and expected inflation are zero and employment is at its natumal level.

Yet, the relatively simple model just described is sufficient to generate an inflationary bias; as a result, socid welfare is lower than it would have been had the monetary authority been credibly committed to a zero money growth (zero inflation) rule. In essence, the monetary authorities and the public are caught up in a kind of "prisoners' dilemma."

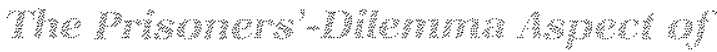

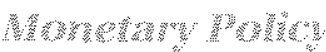

The dilemma is illustrated simply in the following model. "The monetary authority and the public can be viewed as engaged in a game to determine what the level of utput and the rate of inflation will be. The economy's output is determined by a lucas-Sargent aggregate supply function as shown in equation 1 in table 1 , where $y$ is the actual level of output, $y_{n}$ is its

\footnotetext{
shom-rur discrepancies beween the rate of inflation and the rate of monetary growth are abstracted from, in this tiscussion, by assum. ing that those wo rates are equal at all times.

This scenario originated in a well-known example by Kydland and Preseot (1977) and was elaboraled and formulated within an explicily dynamic Iramework by Barro and Gordon (1983b).

This model is based on a static refomulation by Backus and Drifint (1985a).
} 


\section{Table 2}

\section{Payoff Tables for Basic Monetary Policy Game}

1. Policymaker's Payoff Table (from equation 3)

\begin{tabular}{ccc}
$\begin{array}{c}\text { Policymaker } \\
\text { chooses (m) }\end{array}$ & \multicolumn{2}{c}{ Public expects (me) } \\
\hline 0 & 0 & 1 \\
\hline 1 & 0 & -2 \\
\hline
\end{tabular}

II. Public's Payoff Table (from equation 4)

\begin{tabular}{crr} 
Policymaker & \multicolumn{2}{c}{ Public expects (me) } \\
\cline { 2 - 3 } chooses $(\mathrm{m})$ & 0 & 1 \\
\hline 0 & 0 & -1 \\
\hline 1 & -1 & 0
\end{tabular}

natural level and $m$ and $m$ "are the achal and $e x-$ pected inflation rates, respectively. The policymaker's objective function taken to be identical if the social welfare function is shown in equation 2 table 1$)^{*}$

When equation 1 is substituted into 2 , the policymaker's objective function now takes the form shown in equation 3 in table 1 . Taking $m^{*}$ as given, the value of $m$ that maximizes social welfare is $m=1$, resulling in a positive inflation mate. This outcone can easily be seen in the monetary policymaker's payof matrix shown in table 2 (I). If the monetary authority chooses zero inflation, $m=0$, its payof is either 0 or -2 , depending on whether $m^{*}$ equals $0 r^{2} 1$. If it chooses $m=1$, however, its payoft is either 1 or -1 , depending on whether m" equals 0 or 1. Intlation is clearly the dominant strategy from the point of view of the monetary authority; the payots for $m=1$ are higher regardless of what inflation rate the public expects

So far the analysis has focused solely on the monetary policymaker's objective function. However, the public also has an objective function; it is assumed to resist being fooled by policymakers. The public is assumed to maximize a utility function similar to equation 4 in table 1 , taking $m$ as given. Because the public knows the monetary authority's incentive

Since output and employment are positively related, y can also be viewed as a proxy for employment.

The various constarts in equations 1 and 2 have been chosen for simplicity of exposition. The main qualitative point does not depend on the values of those constants. structure, it expects the monetary authority to choose $m=1$; consequently, it chooses $m^{e}=1 .{ }^{11}$ The resultant outcome is an inferior solution, with payoffs of -1 to the monetary authority and 0 to the public.

The inflationary bias occurs because the monetary authority has the incentive to inflate in order to increase employment once the public's inflationary expectations have been set. This incentive is present regardless of whether the public expects a zero or a positive rate of inflation. Because the public recognizes this incentive, it rationally expects a positive rate of inflation; this forces the monetary authority actually to inflate in order to maintain employment at its natural level. As a result, the economy onds up with the same employment level as under a zero money growth rule, but with excessive inflation and lower welfare.

Barro and Gordon (1983b) characterize this solution as "discretionary" because the monetary authonity can choose whatever rate of monetary growth land, hence, inflation it desires, If the monetary authority had been credibly comminted to zero money growth (by a constitutional amendment, for example), the superior solution, $\mathrm{m}=\mathrm{m}^{*}=0$, could have been achieved. But, in the absence of credible commitments on the part of the policymaker, the (Nash) equilibrium to the policy game involves positive and suboptimal inflation."

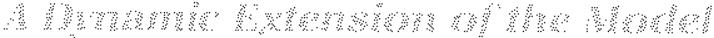

As pointed out by Barro and Gordon (1983b), the prisoners'-dilemma aspect of the policy game carries over to the case in which the policymaker cares about social welfare in both the present and future periods. This can be illustrated by generalizing the objective function of the policymaker as shown in equation 5 :

(5) $W=\sum_{i=0}^{\infty} \beta\left(A\left(m_{i}-m_{i}^{\mathrm{e}}\right)-\frac{m_{i}^{*}}{2}\right)$

$\beta$ is the discount factor applied to future welfare in the policymaker's social welare function. 'The lerm in brackets is the level of social welfare attained in the $i^{\text {th }}$ period. $^{3: 2}$ The constant, $A$, is the marginal rate of substitution between economic stimulation and inflation prevention; the larger $A$ is, the more the policy-

whis is obtained by diferentiating equation 4 with respect to me, equating to zero and solving for $\mathrm{m}^{\mathrm{e}}$.

${ }^{11}$ A Nash equilibrum is defined as a situation in which oach of two sides chooses his best strategy, aking as given the optimal response of the other side.

2This term is a slightly more geneat form of equation 3 . 
maker cares about employment relative to inflation prevention at the margin.

As before, the policymaker chooses $m_{i}$ to maximize the social welfare function in equation 5 , taking $m_{i}^{e}$ as given. Since there is nothing that links the periods, maximization of equation 5 is equivalent to maximization of welfare within each period separately. More formally, the policymaker maximizes equation 6 for all $i$ :

(6) $W_{i}=A\left(m_{i}-m_{i}^{2}\right)-\frac{m_{i}^{2}}{2}$.

As shown in the monetary policymaker's pay off matrix in table 3 , the best choice is $m_{i}=A$ in all periods. ${ }^{13}$

As before, the public resists being fooled. Because it understands the structure of incentives facing the polm icymaker, it rationally sets $m_{i}^{*}=A$ in all periods. Again, the economy ends up with a positive rate of inflation. As before, the discretionary solution is not optimal; zero money growth yields a value of zero to the policymaker if the public expects money growth to be zerol, while the discretionary result vields a social wellare of $-A^{2 / 2}$

It is tempting to aryue that a sophisticated policymakes would elminale this suboptimality by simply consistently setting $m_{1}=0$, thus convincing the public that $m$ should equal zero as well. The public, however, knows that, as soon as they expect inflation to be zero, the policymaker can increase welfare $\left(t 0 A^{2} / 2\right)$ by reverting to the discretionary inflation solution. Because the policymaker will revert to discretion in this case the public will ationally expect that inflation will equal $A$. As a resull, the best solution, $m_{i}=m_{i}^{*}=0$ is unstable, whereas the discretionaty (Nash solution in, $=m_{i}^{*}=A$ is stable ${ }^{*}$

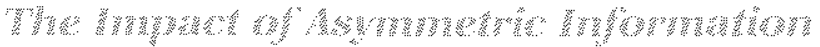

To this point, the public and the policymakes were assumed to have the same information. Suppose, however, that this is not the case. Backus and Driffil: 1985a, 1985 bl consider a model in which the policy. maker is one of two types: "weak" or "strong." If the policymaker is weak, his payot matrix is the one shown in table 2 (1) or 3 It he, therefore has an incentive to generate inflation. If the policymaker is strong, however, he always prefers zero intlation.

t5 1 is obtained from the firstorder condition for the maxmization of (6)

:The dynamic inconsistency of the first best solution was otignally noted by Kydland and Prescott (1977).
Table 3

\section{Payoff Tables for a Typical Period in the Dynamic Monetary Policy Game}

1. Policymaker's Payoft Table (from equation 6)

\begin{tabular}{|c|c|c|}
\hline \multirow{2}{*}{$\begin{array}{l}\text { Polloymaker } \\
\text { chooses }(m)\end{array}$} & \multicolumn{2}{|c|}{ Public expects (m) } \\
\hline & 0 & $A$ \\
\hline 0 & 0 & $-3 A^{2} / 2$ \\
\hline$A$ & $A^{E / 2}$ & $-A 2$ \\
\hline
\end{tabular}

II. Public's Payoft Table (from equation 4)

\begin{tabular}{|c|c|c|}
\hline \multirow{2}{*}{$\begin{array}{l}\text { Policymake } \\
\text { chooses }(\mathrm{m})\end{array}$} & \multicolumn{2}{|c|}{ Public expects (m) } \\
\hline & 0 & $A$ \\
\hline 0 & 0 & $-\mathrm{A}^{2}$ \\
\hline$A$ & $A^{2}$ & $\dot{0}$ \\
\hline
\end{tabular}

In the beginning, the public assigns some probability to the condition that the policymaker is strong and, therefore, will not inflate. Weak policymakers are tempted to inflate. However, since they maximize welfare over several periods, they have an incentive to appear stoong, at least initialy, to discotrage inflationary expectations. The public watches the actions of the policymaker and adjusts its probability accordingly that the poltcymaker is strong. This piobability is considered to be a measure of credibility.

As long as the policymaker does not inflate, the public assigns some positive probability to the event that the policymaker is strong. If the policymaken inflates even one time, however, he immediately reveals himself to be weak. Because strong policymakers never inflate, there is no way that a policymaker can reestablish his Iost reputation. Consequently, once inflation starts, it continues forever.

Backus and Drifill fomulate this problem as a dynamic, mixed-strategies Bayesian game using kreps and Whon's $(1982 \mathrm{a}, 1982 \mathrm{~b})$ notion of sequential equilibrium. ${ }^{15}$ This fomulation captures the incentive of the weak policymaker to act temporarily as it he were strong in order to mantain finde inflationary expecfations at a lower level. It also provides the public with a ratonale for watching the actions of the policymaker, at least unth it is known that he is weak. This analys is resticted, however, by the fact that the policymaker can be one of ony wo bnchanging lypes. As

15A similar anaysis appears in Berro (1985) 
a consequence, once a reputation is destroyed, it cannot be rebuilt. Those features of the analysis are inconsistent with the observed frequent reversals in the rate of monetary growth in the United States, England and other democracies.

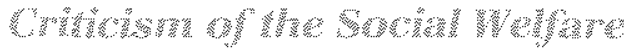

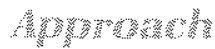

Because equation 2 , or its multi-period variant, equation 5 , is used frequently as a social welfare function in the theoretical literature on central bank behavior, it is important to examine why it takes this specific form. ${ }^{76}$ The negative effect of inflation on social welfare results from the familiar loss of consumer surplus that inflation produces through the decrease in the public's real money balances. The positive association between deviations of employment from its natural level and social welfare can be explained by the existence of various labor market distortions llike taxes and unemployment benefits) that make the natural level of employment too low (Barro and Gordon, 1983b). Another explanation, offered by Canzoneri (1985), is that the presence of large unions keeps real wages too high and the natural employment level too low.

The view that the existence of disfortionary taxes necessarily indaces an intationary bias on the part of a socially minded central bank mases sevemal quesLions. First this notion relies only on the distortionary effect of taxes on the allocation of time between labos and leisure, neglecting the atility from the public good that is financed by these laxes. Since individuals lake the level of the public good provided by government as being independent from their individual labon meisure decisions, while the centmal bank lakes into considerm ation that this level depends on total ax collections which depend in tum on total employment $\ldots$.... there is atso an extemality. If the socially optimal level of the public good is higher than the amount that wan be financed through the taxes collected in the absence of central bank intervention, the bank has an incentive to increase fotal tax collections. Whether this implies that it has an incentive 10 increase employment or decrease it depends on the tax structure and the elasticity of labor demand. In the lattet case, the tax distortion and the public good extematity have conflicting effects on the socially optimal level of employment in relation 10 its general equilibrium level in the absence of central bank intervention. Cukierman and

"For exampte, when there is too much of the public good in the nointervention equilbitum, the central bank has a teflatonary bias, provided labor demand is sufficiently elastic.
Drazen 1986! show within a nominal contracts fiamework of the Fischer 1977 , wpe that if the demand for labor is sufficiently inelastic, the last effect dominates, producing an incentive to decrease employment via unanticipated deflation. Furthemore, the range of cases in which the central bank tums out not to have an inlationary bias is by no means negligible." The upshot is that a socially minded policymaker facing distortionary labor taxes should not be automatically presumed to possess an inflationary bias.

Second, if the level of employment is too low because of distortionary laxes, a ful malysis of the behavior of policymakers should be able to determine simutaneously both inflation and oher taxes, laking into consideration the lax reventes from inflation. Such an extension is considered by Alesina and Tabellini 19985 within a framework in which fiscal and monetary policies are determined by two independen authorities. An important implication of this framework is that the resulting equilibrium rate of inflation is not necessarily suboptimal. This will be discussed more fully in the second installment of this survey.

Finally, the social welfare function interpretation of the policymaker's objectives does not fil very well with the notion that there are two alternative types of policymakers. One possibility might be that there ate two altemative welfare functions that characterize the economy. If that is the case, however, it seems peculiar that the relevant one is known ony to the policymaker. Indeed, this possibility seems untenable. An other possibility is that, while the objective function of the weak policymaker is identical to the social welfare function, the strong policymaker's objective function is different from it. Once it is recognized that the objectives of the policymaker may differ from the social welfare function, however, there is no reason to restrict the analysis to only a single alternative formulation. Consideration of a variety of altematives is handled by a political interpretation of the policymaker's objective function.

\section{Trin

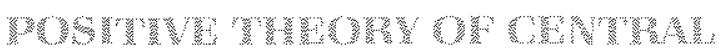

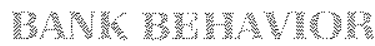

Recent work in both economics and political science suggests that monetary policy is not totally divorced from the general political process, for exam-

is addition to the papers quoted above. those include Barro and Gordon (1983a), Backus and Driffil (1983b), Fogoff (1985) and, to some extent, Canzoneri (1985). 
ple, in spite of the Federal Reserve's statutory independence from other branches of government, monetary policy is partly responsive to the desires of the President, Congress, the financial community and periodically some other less visible institutions or groups."

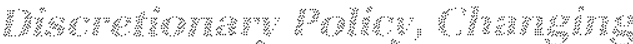

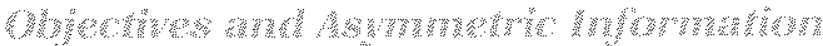

The central bank knows both the extent of the political pressure focused on it to change monetary policy at any given moment and how likely it is to accommodate this pressure. Further, the formation of effective coalitions determined to change the course of monetary policy is subject to large stochastic elements. Cukierman and Meltzer (1986a) formalize this notion with an objective function similar to equation 5 in which the monetary authority's marginal prefer-

${ }^{18}$ The precise channels through which these responses are elicited are subtle and, at times, efude precise formulation because the President, Congress and the Federal Reserve all have a common interesi in preserving an image of the Central Bank as an independent, apolitical institution.

Kane $(1980,1982)$ has argued that the Federal Reserve performs a scapegoal function for the President and Congress. In return, the Fed gets a fair degree of independence which is necessary in order to credibly perform the scapegoat function. A general discussion of the political approach in the context of monetary reform appears in Wilet and McArthur (1985).

Weintraub $(1978$, p. 356$)$ concludes after summanizing the history of the post-accord monetary policy that much of this policy ". . can be explained just by noting who the President was when the policy under review was in effect." In a study of Presidential influence on monetary policy, Beck (1982) concludes that presidential political demands are somehow transmitted to the Fed. Beck notes that the transmission mechanism requires further study but that it seems clear that presidential preferences are an important determinant of Fed policymaking (Beck, 1982, p. 443). Woolley (1984) holds a similar view. Hetzel (1985) argues that current institutional arrangements allow Congressmen to pass on political pressures of various consituent groups to the Fed while avoiding association with the consequences that adversely affect the welfare of olher groups. This explains Congress' consistent preference (noted by Woolley, 1984, chapter 7) for attempting to influence monetary policy through a variety of threats to limit the Fed's instifutional autonomy rather than through an explicit mandate to guide monelary policy (Hetzel. 1985, p. 7 ). Since the autonomy of the Fed depends on Congress, it must be at least somewhat sensitive to the wishes of Congress provided the Fed values autonomy.

Both Congress and the Presidency are institutions largely concerned with various redistributional considerations. As a consequence the Fed is, possibly to a lesser degree, also sensitive to redisiributional considerations. In addition, the Fed is not indifferent to the interests of groups with which it deals on a dally basis, e.g., banks and the financial commumty in general (Woolley, chapter 4). Arthur Burns (1979) appears to share the view that the Fed is not a totally free agent. He believes that the Fed can work to achieve price siability only if the policy does not adversely affect production and employment and does not iritate Congress. In Burns' words, the role of the Fed is to continue "probing the limits of its treedom to undernourish ... inflation" (Bums 1979, p. 16). ence for economic stimulation vs. inflation prevention shifts randomly through time. In this formulation, the constant marginal rate of substitution $A$ is replaced by a random variable $x_{i}$ which reflects the current com promise that the central bank strikes between advocates of economic stimulation and advocates of price stability. ${ }^{19}$

The crucial element in this formulation is that $x_{i}$ is in a continuous state of flux and is not known by the geneal public. Fowever, the public can rationally and gradually detect changes in $x_{i}$ by observing changes in the ate of growth of the money supply; this detection activity provides an explanation for "Fed watching." Since the public is unaware, at any given moment, of the precise value of the central bank's current $x_{i}$, the central bank is able to affect output through suprise money cteation.

There are both similarities and differences between the social welfare and the political interpretation of the policymaker's objective function adopted in this section." The political approach views the policymaker as choosing money growth to maximize the expected value of

(7) $\sum_{i}^{\infty} \beta_{0}\left[x_{i}\left(m_{i}-m_{i}^{\text {e }}\right)-\frac{m_{i}^{2}}{2}\right]$,

where $x_{i}$ is a stochastic variable with some persistence.".1

Equation 7 is formally equivalent to equation 5 with the sole exception that $A$ is replaced by $x_{i}$; however, its interpretation is quite different. Equation 7 reflects the curvent political compromise between competing objectives preferted by the policymaker; it is not a social welfare function. Similarly, the discount factor $\beta$ reflects the time preference of the policymaker as an

${ }^{19}$ The motivation of either group of advocates may be mostly distributional. Some people are relatively more adversely affected by unemployment than by intlation. Changes in $x$, reflect changes in (a) the relative sizes of those groups, (b) the degree to which they are adversely affected by infiation and unemployment and, (c) the perceptions of the central bank about those changes and the degree of urgency in accommodating them. In some long-run sense, the central bark may be responding to the desires of voters. However, the public does not know the extent to which the central bank currently responds to voters.

aThe following discussion draws heavily on Cukierman and Melzzer (1986a).

2The precise stochastic structure is:
(a) $x_{i}=A+p_{i}$
$A>0$
(b) $p_{i}=p p_{i-i}+v$
$0<p<1$
(c) $\mathrm{V}_{i} \sim \mathbf{N}\left(0, \sigma_{v}^{2}\right)$.

$A$ is a positive, publicly known, constant and $p_{z}$ a first-order Markoff process whose realization is known only lo the poticymaker. 
institution with its own priorities rathes than the social rate of discount ${ }^{22}$

The political interpretation avoids some of the criticisms directed toward the social welfare interpretation for the policymaker's objective function. Thus, while it is diffeult to explain why the monetary authority should be better informed about the social welfare function than the public, it is easy to believe that the policymaker is better informed about $x_{i}$, which simply reflects the policymaker's curcenty preferred compromise between conflicting objectives.:

The policymaker acts in a discretionary manner in planning the rate of money growth (and inflation, taking into account the tradeofils he faces between current stimulation and the public's future inflationary expectations. In particular, the policymaker knows that current actions which raise future inflation expectations make it more costly in terms of inflation to further stimulate the economy in the future. The policymaker chooses both the current money growth and plans for future money growth to achieve a maximum for the expected value of the objective function in equation 7 .

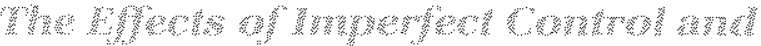

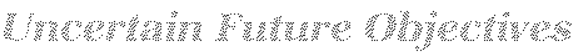

The decision pattem just described is complicated by wo additional conditions. First, the policymaker is assumed to have imperfect control of the money supply - actual money growth deviates randomly from the growth planned by the monetary athority as shown in equation 8 ,

(8) $\mathrm{m}_{\mathrm{i}}=\mathrm{m}_{\mathrm{i}}^{\mathrm{7}}+\eta_{\mathrm{i}}$

where mi is the rate of monelary growth planned by the policymaker for period $i$ and $\eta_{i}$ is period its realization of a white noise process, the variance of which is determined by the precision of existing monetary control procedures. ${ }^{-2}$

${ }^{22}$ This formulation is consistent with the views of long-time students of the Fed like Lombra and Moran (1980), Lombra (1984) and Kane (1982) concerning the Federal Reserve System. In particular, Kane (1982, p. 207) wites:

"Inherent in the utoplan vew of the Fed is the presumption that the Fed can somehow evaluate the public interest on its own. In the contemporary United States, it is hard to conceive of the public interest except as a delicate balance of conflicting private interests."

${ }^{23}$ In addition, the pointical approach does not rely on the notion that distortionary taxes necessarily induce policies biased toward inflation

${ }^{24}$ The case in which the level of precision in monetary control is a choice variable is considered later in this paper.
Second, the policymaker is assumed to be uncertain about his own future objectives. He knows, however, their current values and uses their persistent structure (see footnote 21 ) to derive optimal predictors of future values of $x_{i}$. These predictions are necessary, even though no commitment to any particular future money growth is required, because he knows that the current rate of monetary growth will affect future inflationary expectations. If he expects to care more about employment in the future than he does now, he will increase his ablity to create suprises at relatively low inflation in future periods by choosing a relatively low current monetary growh. If he expects to care less about employment in the fulure than he does at present, he will choose faster curment monetary growth (and faster inflation.

The important point is that the policymaker must predict his own uncertain objectives in the future when choosing the current rate of money growth. This uncertainty arises because he does not currently know for certain what the future optimal (for him) balance will be between pressures exerted by various groups and institutions. The more stable the underlying socio-political environment, the smaler this uncertainty will be. The uncertainty can be measured by the variance of the policymaker's objectives; this is denoted as $\sigma_{v}^{2}$ (see footnote 21 ).

Cukieman and Melzer (1986a) (CM hereafter) show that the solution to the policymaker's decision problem in equation 7 is

$19 m_{1}^{p}=B_{0} A+B p_{1}$

where $B_{0}$ and $B$ are positive constants that depend on the parameters of the policymaker's objective function and the precision of monetary control, and where $p_{i}$ is the mandom part of $x_{i}$ (see footnote 21 ). When equation 9 is substifuted into equation 8 , actual money growth can be expressed as

(10) $\mathrm{m}_{\mathrm{i}}=\mathrm{B}_{\mathrm{o}} \mathrm{A}+3 \mathrm{p}_{\mathrm{i}}+\eta_{\mathrm{i}}$

This model assumes that the public does not know the current state of the policymaker ${ }^{*}$ s objectives $-x_{i}$ or $p_{i}$ is known only by the pollcymaker." The public, however, knows the policymaker's decision rule in equation 10 and has observed nin each period up to and including the previous one. Since mas some degree of persistence, pasi values of money growh convey noisy, but meaningful, information about future money growth to the public. The noise is induced by the control error, $\eta_{\mathrm{i}}$.

25nce $A$ is public intormation, knowledge of $x_{i}$ is equivalent to knowledge of $p_{\text {. }}$. 
The optimal predictor of future money growth adjusts slowly to actual changes in observed money growth; specifically,

(11) $m_{1}^{e}=(\rho-\lambda) m_{i-1}+\lambda m_{i-1}^{e}+(1-\rho) B_{01} A^{36}$

The parameter $A$ is detemined by the degree of persistence in the policymaker's objectives, the precision of monetary control and the degree of instability in the political environment of the policymaker as measured by $\sigma^{\prime}$. Because $\lambda$ is bounded between 0 and $\rho$, the value of $p-\lambda$ is positive.

Equation 11 specifies that expected money growth is a weighted average of last period's money growth, $m_{i-1}$ the last period's expectation, $m_{i m 1}^{e}$ and $B_{0,} A^{2 z}$ Inflationary expectations partialy adjust to changes in actual and planned money growth because, as implied by equation 10, actual money growth is influenced both by persistent changes in the objectives of the policymaker and by transitory control errots. The public, therefore, rationaly attributes only part of the fluctuations in $m$ to persistent changes in the objectives of the policymaker.

When choosing the rate of money growth, the policymaker lakes into considefation its effect on future inflation expectations (equation 11). In fact, the policy maker's decision rule (equation 9 ) is the solution to maximization of the expected value of his objective function (equation 7 ), given how the public's infation expectations are formed lequation 1 .

The equilibrium formed from these equations is self-fulflling. Given the decision rule of the policymaker (equation 9 ) and the money growth equation (equation 10), the best predictor of future inflation is given by equation 11. Conversely, given this predictor the bes strategy for the policymaker is shown by equation 9, which induces the money growth shown by equation 10 .

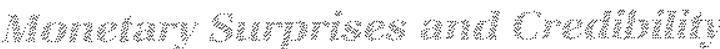

The self-fufflling nature of equhbrum does not mean that there are no monetary surpuses, In lact, monetary surprises occur frequently; their expected value however, is zeno. The reason for frequent monetary surprises is that the objectives of the policymaker

\footnotetext{
2 In staristical terms $m_{i}$ is the expected value of $m_{i}$ conditioned on $m_{i-1} ; m_{i-2} \ldots$

${ }_{27}$ Taking unconditional expected values on both sides of equation to, $B_{0}$ A can be recognized as the unconditional mean money growh.
}

are continually changing; the public, however, becomes aware of those changes only gradually by observing past rates of inflation. Thus, when the policymaker becomes relatively less concemed about inflation prevention, the public recognizes this policy change only gradually. In the interin, actual inflation is higher than expected and employment is above its naturat level. Conversely, when the policymaker be comes relatively more concemed about inflation prevention, inflation is lower than expected and output is below its natural level until the public recognizes this policy change.

The public monitors changes in monetary growth because these figures provide additional infomation about future inflation. This incentive to monitor money growth explains why resources are devoted to Fed watching (Bull, 1982; Hardouvelis, 1984). In the absence of asymmetric infomation, there would be no reason for this activity.

Recently Fischer (1984) has stressed the importance of the speed with which the public's expectations adjust for determining the costs of disinflation policy actions. The faster expectations adjust, the lower the output costs of disinflation will be. CM show that the speed with which expectations adjust is systematim cally related to the precision of monetary control. In particular, the less precise monetary control is, the larger is $\lambda$ in equation 11 and the longer it takes for the public to recognize that the policymaker's objectives have changed.

CM conceve of credibility as the speed with which the public recognizes that a change in the poticy maker's objectives has actually occurred. This concept of credibility seems appropriate when policy is discretionary and the policymaker's objectives known only to him are in constant flux. "The parameter $\lambda$ from equation 11 is a nalural and convenient measure of credibility. ${ }^{23}$ sing this measure, credibility is higher, the nore precise monetary control is the lower the variance of $\eta$.

It has been observed that shont pun considerations often are given relatively large weight in the actua conduct of monetary policy 3 in tems of the frame-

\footnotetext{
26 With a highe $\lambda$, tess weight is given to the last observed inflation, $m_{i-1}$, and more weight is given to the last intation expectation, $m_{m-1}$

${ }^{29}$ As shown in equetion (10b) of $C M, \lambda$ is a known function of $\sigma_{r}^{2}$ and $p$ as well so that credibility is also influenced by the instabitity of objecives and their persistence.

so For example, see Brunner and vivetzer (1964), Kane (1977, 1980$)$, Plerce (1980), and Mayer (1982).
} 
work presented here, this observation means that the policymaker has a high time preference ( $\beta$ in equation 7 is lowl. CM show that the higher the policymaker's time preference, ceteris paribus, the higher the variability and the uncertainty in the rate of monetary growth.

The characterization of credibility differs somewhat among various models of monetary policy behavior. As explained above, in the CM formulation, credibility is a parameter. It measures the speed with which the public detects the actual changes in the policymaker's objectives. CM characterize credibility under discretion and asymmetric information. In models with two types of policymakers, credibility or reputation is a state variable. ${ }^{37}$ It is the current subjective probability assigned by the public to the event that the policymaker is strong.

Barro and Gordon (1983b), on the other hand, focus on the credibility of the first-best, non-inflationary policy and point out that this policy is "incredible" under discretion and symmetric information.

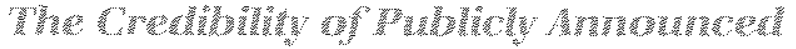

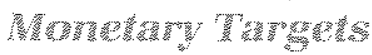

Cukierman and Meltzer (1986b) extend the politically based model to the case in which the policymaker makes noisy leg., announcements of target ranges rather than a specific level but unbiased announcements about his future plans ${ }^{32}$ In this case, the public finds it optimal to use the information from past announcements in addition to past monetary growth to form its expectations. In comparison to the case in which no announcements are made, noisy announcements never increase (and usually decrease) the public's uncertainty about future monetary growth. In the case in which announcements are made, credibility is naturally defned as the deviation between the current announcement and the public's expectation. This deviation depends on the relative amounts of noise in both the control of the money supply and the announcements, as well as on the

3:Backus and Driffill (1985a, 1985b); Barro (1985).

32House Concurrent Resolution 133, and later the HumphreyHawkins Act, require the Federal Reserve to announce planned rates of growth for principal monetary aggregates. The purpose of this legistation is to provide the public and Congress with more precise information about the particular monetary actions contemplated by the monetary authority. Announcements are (or have been) made in Germany, Japan, U.K., France, Canada, Australia and Switzerland. magnitude of recent changes in the policymaker's objectives.

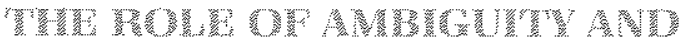

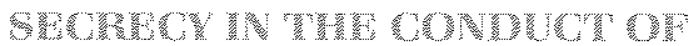

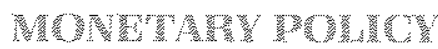

Various students of central bank behavior have suggested that the low credibility and ambiguity in the specification of objectives by central banks may be, to some exfent, deliberate. ${ }^{37}$ The political approach presented in the previous section provides an explanation for this inclination for policy ambiguity. Consider the case in which the level of noise in monetary control is a choice variable rather than a technological datum. The policymaker will choose, once and for all, the variance of the monetary control error that maximizes the unconditional expected value of his objective function, which, for this discussion, is equation $7 .^{34}$

For any given level of control precision, the planned and actual money growth are determined by equations 9 and 10 , respectively, and the public's inflationary expectations are deternined by equation 11. By choosing more noisy control procedures, the policymaker increases $\lambda$ in equation 11; this, in furn, increases the length of time it takes the public to recognize a change in the policymaker's objectives.

Whether a longer recognition period is desirable, however, depends upon the change in policymaker objectives. It is advantageous when the policymaker becomes relatively more concerned about economic stimulation; in this case, he can produce positive surprises for a longer time period. When the policymaker becomes relatively more concerned about inflation, however, a higher $\lambda$ is detrimental; it lengthens the period of recession and negative surprises necessary to decrease inflation. Thus, the policymaker would like to have lower credibility (in the CM sense)

\footnotetext{
3in recent hearings before the Joint Economic Committee, Lombra argues that the observed incompleteness in the specification of quantitative goals for monetary policy is deliberate (Lombra, $1984 \mathrm{p}$. 113). Similar views are expressed in Brumer and Melzer (1964) and Lombra and Moran (1980). The penchant of the Central Bank for secrecy tas recently been revealed in the legal record of a case in which the Federal Open Market Committee (FOMC) was sued under the Freedom of Information Act of 1966. The suit required the FOMC to make public immediately after each FOMC meeting the policy directives and minutes for that meeting (Goodfriend, 1986). The Federal Reserve atgued the case for secrecy on a number of different grounds. The important issue from the point of view of this section is that the Federal Reserve altempted to preserve its information advantage.

${ }^{3}$ the following discussion is based on section VI of Cukierman and Meltzer (1986a).
} 
when he becomes more interested in stimulating employment and higher credibility when he becomes more interested in preventing inflation.t.

Although positive and negative surprises cancel each other out on average, the policymaker may still find it advantageous to choose control procedures that slow down public recognition of changes in his objectives. Greater ambiguity provides the policy maker with greater control in timing monetary surprises. When there is more ambiguity about policy, he can create larger positive surprises when he cares more about stimulation and leave the inevitable negative surprises for periods in which he is relatively more concerned about inflation.

Thus the policymaker makes a once-and-for-all (politically) optimal choice of control procedures that also determines his public credibility. This choice is systematically related to the degree of time preference of the policymaker; in particular, policymakers with a stronger time preference will choose less precise con trol procedures.

Moreover, the higher the degree of uncertainty in the policymaker's objectives, the more likely he is to choose less precise control procedures and lower credibility. When the policymaker's objectives are nelatively unstable, a rational public will give more weight to recent developments in forecasting the future rate of growth of money. Consequently, for a given precision in monetary control, it is more difficult to exploit the benefits of monetary surprises. By decreasing the precision of monetary control, a policymaker with relatively unstable objectives can partially offset this effect by increasing the length of time it lakes the public to detect a given shift in its objectives.

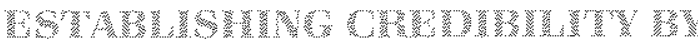

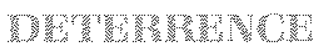

Ever since Kydland and Prescott (1977) pointed out that the monetary authority and the public are caught

\footnotetext{
${ }^{35}$ This may explain why public concern about lack of credibility is aroused mostly when disinflation is considered. Not much concern was expressed at the end of the ' 60 s and the '70s complaining about the lack of credibility of the increased inflationary poticies of those times.

36. Long-time students of the Fed like Bunner and Meltzer (1964), Kane (1977, 1980), Mayer (1982) and Pierce (1980) suggest that the Federal Reserve engages primarily in "fire fighting." In terms of the model, this would imply a high rate of time preference (low $\beta$ in equation 7). In conjunction with the result obtained by $\mathrm{CM}_{\text {, this }}$ implies that the Fed is likely to have a preference for incomplete control procedures and imperfect credibility.
}

in a prisoners' dilemma resulting in excessive inflation, it has become natural to look for mechanisms that would eliminate or reduce this inefficient result. Obviously, a first-best solution would be to effectively commit the policymaker to a zero inflation policy ${ }^{3}$ If such commitments are impossible, second-best solutions may be sought.

One second-best solution that relies on deterrence within a symmetric information environment has been suggested in Barro and Gordon (1983a). It can be illustrated using the relationships previously described. The basic idea is that the public must determine its inflation expectation in a way that deters the policymaker from choosing its optimal discretionary rate of inflation, for example, $A$ in equation 6 . Suppose that the policymaker announces a fate of inflation, $\mathrm{m}^{*}$, that is lower than A. The public then sets its inflationary expectation for the current period as follows: If actual inflation in the previous period accords with expectations, they expect that inflation will continue at $\mathrm{m}^{*}$. If the previous period's inflation does not accord with expectations, they expect instead that the monetary authority will inflate at the higher discretionary rate, $A$. Thus, whenever the monetary authority inflates at rate $A$ rather than at its announced rate $\mathbf{m}^{*}$, the public "punishes" it for one period by believ" ing that it will continue to do so in the next period as well.

The monetary authority maximizes its objective function (equation 5) subject to the public's behavior ${ }^{39}$ In considering whether to inflate at rate $A$ today, it compares the difference between the current value of social welfare when it inflates at rate $A$ rather than at rate $\mathrm{m}^{*}$ (given that the public expects $\mathrm{m}^{*}$ ) with the discounted value of the loss in next period's welfare because the public's inflation expectations increase from $m^{*}$ to $A .^{* 0}$ As long as the latter term (which acts as a deterrent) is larger than the former term (which

\footnotetext{
${ }^{3}$ Or to whatever the optimal rate of inflation happens to be.

2un spite of its popularity, this lerm does not quite catch the function of this strategy. The idea is not to punish the monetary authority but rather to deter it from inflating at the discretionary rate $A$. This observation is due to Edward Green.

3The example here is within the social wellare framework in which the polcymaker's objectives are identical to the social weifare function.

40 The calculation of this loss is based on the understanding that the monetary authority chooses A also in the nexperiod. The reasor is that this choice yields a better value io its objective function than the choice $m^{*}$. Given that, in the next period, expectations are at $A$, inflation a $A$ yields $-A^{2} / 2$ to the policymaker whereas inflating at $m^{*}$ yields $A\left(m^{*}-A\right)-\left(m^{*}\right)^{2} / 2$ which is smaller for any $m^{*}<A$.
} 
represents the temptation to inflate at rate $A$ ), the policymaker picks $\mathrm{m}^{*}$, the lower inflation rate.

Formally (from equation 5), the condition for effective deterrence of the higher inflation $A$ is

(12) $\frac{\beta}{2}\left[\left(A^{2}-\left(\mathrm{m}^{*}\right)^{2}\right]>A\left(A-\mathrm{m}^{*}\right)+\frac{\left(\mathrm{m}^{*}\right)^{2}-A^{2}}{2}\right.$

The left-hand term is the discounted value of the loss in next period's welfare due to the increase in expectations. The righthand term is the gain in current welfare induced by higher current employment:"1

The lowest credibly sustainable rate of inflation can be found by equating the two sides of equation 12 and solving for $\mathrm{m}^{*}$. The solution is shown in equation 13 :

(13) $\mathrm{m}^{*}=\frac{1-\beta}{1+\beta} A$.

This rate is higher than the first-best zero intlation, but lower than the rate of intlation, $A$, that would occur in the absence of deterence. Equation 13 expresses the best enforceable rule as a function of the discount factor $\beta$. The higher the degree of time preference, the higher the minimum sustamable rate of intation will be."3 Once this mechanism is in place, it is selffulfiling: the public believes that the policymaker will inflate at rate $\mathrm{m}^{*}$ and indeed, the policymaker does so. In the absence of commitments, therefore, a second best lower rate of infation can be credibly sustained by an appropriate deterence mechanism.

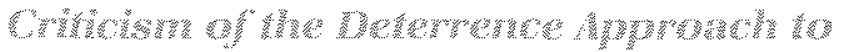

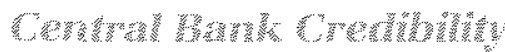

The deterrence approach to enhancing central bank credibility has been interpreted by some (e.g., Barro and Gordon, 1983a) as a positive theory of inflation.4 Taylor (1983), however, faises doubts about its usefilness as a positive theory of inflation on the grounds

Anote that the ideal inflation expectation, $m^{*}=0$, cannot be sustained if there is positive time preference. It would require the inequality

$$
\beta \frac{A^{2}}{2}>\frac{A^{2}}{2}
$$

to hold, however, this condition camot be satistied when $B<1$. A somewhat higher rate of inflation can be sustained by this mechanism even for $\beta<1$.

"Since this is a quadratic equation there are two rogts, the smallest of which corresponds to the minimum credibly sustainable intlation.

3obvicusy other deterence mechanisms will yield different sustainable ranges for the rate of inflation.

¿al? also can be considered trom a nomatue poin of viow, in which it represents a mechanisn that mproves weifare in comparison to a situaton in which this mechanism is absent. that, in other similar dynamic inconsistency situations, society has found ways to circumvent the problem. He cites patents as a device for eliminating the dynamic inconsistency problems faced by inventoms as an example.

In addition, the deterrence equilibrium implies that the rate of inflation remains constant (Canzoneri, 1985). This implication is clearly at odds with observam fions that both inflation and monetary growth fluctuate substantially over time. Furthen, the deterrence equilibrium depends critically on the punishment strategy assumed in the analysis. Consequently, the infinite-horizon monetary policy game has multiple Nash equilibria with no mechanism for choosing among them (Backus and Driffill, 1985a). Therefore, any specific link between the current actions of the policymaker and the future expectations of the public is strictly arbitrary.

Finally the deterrence strategy may be subject to a free rider problem. ${ }^{95}$ Individuals may simply find that it is not worthwhile to achieve a lower rate of inflation via the deterrence mechanism if the private costs of monitoring the policymaker's actions are higher than the marginal private benefiss. This problem, while of lesser importance in the context of aligopoly theory from which the formal structute of the deterrence equilibrium above has originated, may be serious if the public is composed of many individuals. Each individual may rely on the others to deter the policymaker from acting in a discretionary manner, thus eliminating the deterrence mechanism that made the lower inflation policy credible in the first place.

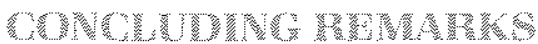

Traditonal economic analysis generally has treated policymakers' behavior as determined exogenously. In contrasi, recent literature on cental bank behavior focuses expicily on how the motives, constraints and information of policynakes and the public detemine monetary policy outcomes.

Some analvsis use a political explatation of the policymaker's objectives; others identiv the policy-

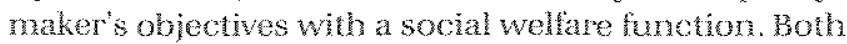
approahes show how an inflationary bias ars cread by inemations beween the policymaker and the

\footnotetext{
s Suggesid by Eward Gron in comprsation.

4s. Frodman (1971, 1977) conkins an eary discussion of the deterrence sirategy in the context of oligopoly.
} 
public. Models utilizing the political approach, however, seem to be better able to explain two widely observed phenomena: the preference of monetary authorities for ambiguity in public policy pronouncements and the large swings in actual rates of money growth and inflation. Unfortunately, existing political models have not identified explicitly how various groups and political institutions combine to shape the objectives of the monetary authority. ${ }^{* i}$

More recently, models have appeared that combine explicitly some interaction between political behavior, institutions, and economic policymaking. Some of these models rely on the existence of long-term contracts to induce a tradeoff between lower inflation and stimulation. A central theme of this literature is the optimal design of monetary institutions. Those developments will be described in the second part of this survey.

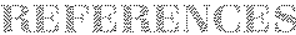

Alesina. Alberto, and Guido Tabellini. "Rules and Discretion with Non Coordinated Monetary and Fiscal Policies," manuscript (September 1985).

Backus, David, and John Driffll. "Inflation and Reputation;" American Economic Review (June 1985a), po. 530-38.

"Rational Expectations and Policy Credibilify Following a Change in Regime," Review of Economic Studies (1985b), pp. $211-21$.

Barro, Roben J. "Peputation in a Model of Monetary Policy with Incomplete information," manuscript. University of Rochester (February 1985). Forthcoming Journal of Monetary Economics.

Barro, Robert J., and David B. Gordon. "Rules, Discretion and Reputation in a Model of Monetary Policy," Joumal of Monetary Economics (ululy $\$ 883 a$ ), pp. $101-22$.

"A Positive Theory of Monetary Policy in a Natural Rale Model," Joumat of Political Economy (August 1983b), pp. 589-610.

Beck, Nathaniel. "Presidential Intuence on the Federal Reserve in the 1970s," American Jounal of Political Science (August 1982). pp. $415-45$.

Brune: Karl, and Allan H. Meltzer. The Federal Reserve Attachment to Free Reserves, House Committee on Banking and Currency, Washington, D.C. (1964).

Bull, Clive. "Rational Expectations, Monetary Data and Cenital Bank Watching:" Gionale degli Economisti e Annali di Economia (January/February 1982), pp. $31-40$.

Bums, Arthur F. The Anguish of Central Banking, per jacobsson Foundation, Belgrade, Yugosiavia (1979).

While there is a substantal amount of descriptive naration (e.g.; Wooliey, 1984; and Hetzel, 1985), there is very title analyticai discussion of these seves.
Canzoneri, Matthew B. "Monetary Policy Games and the Role of Private Information," American Economic Review (December 1985), pp. 1056-70.

Cukierman, Alex. Inflation, Stagflation, Relative Prices, and imperm fect Information, Cambridge University Press, Cambridge, London, New York (1984), pp. 1056-70.

Cukieman, Alex, and Allan Drazen. "Do Distortionary Taxes In" duce Policies Biased Towards Inflation?: A Microeconomic Analysis," Tel-Aviv University (August 1986).

Cukierman, Alex, and Allan H. Meltzer. "A Theory of Ambiguity, Credibilify and Intzation Under Discretion and Asymmetric Intormation," manuscript, Carnegie-Mellon University (February 1986a). Forthcoming Econometrica

"The Credibility of Monetary Announcements," forthcoming in Manfred J.M. Neumann, ed., Monetary Policy and Uncertainty (Nomos Verlagsgesellschaft. Baden-Baden, Germany, 1986b).

Fellner, William. Towards a Reconstruction of Macroeconomics: Problems of Theory and Policy (American Enterprise Institute, 1976).

Fischer, Stansey. "Long Term Confracts, Rational Expectations and the Optimal Money Supply Rule," Journaf of Political Economy (April 1977), pp. 191-206.

"Contracts, Credibility and Disinflation," Working Paper No. 1339 NBER (April 1984).

Friedman, James. "A Non Cooperative Equilibrium for Supergames," Review of Economic Studies (danuary 1971), pp. 861-74.

Oligopoly and the Theory of Games (North Holland Publishing Company, Amsterdam, New York, Oxford, 1977).

Goodfriend, Marvin. "Monetary Mystique: Secrecy and Central Banking," Journal of Monetary Economics (January 1986), pp. 6392.

Haberler, Gottfied. "Notes on Rational and irrational Expectations," Reprint No. 111, American Enterprise Institute (March 1980 ).

Hardouvelis, Gikas A. "Market Perceptions of Federal Reserve Policy and the Weekly Monetary Announcements," Journal of Monetary Economics (September 1984), pp. 225-40.

Hetzel, Robert L. "The Formulation of Monelary Policy," manuscript, Federal Reserve Bank of Richmond (Augusi 1985).

Kane, Edward J. "Good Intentions and Uniniender! Evil: The Case Againsi Selective Credit Alocation," Joumal of Money, Credit and Banking, Part 1 (February 1977), po. 55-69.

Politics and Fed Policymaking: The More Things Change the More they Remain the Same," Joumal of Monetary Economics (Aprii 1980), pp. 199-212.

"External Pressure and the Operation of the Fed" in R.E. Lombra and W.E. Wite, Pollical Economy of miemational and Domestic Monetary Relations (lowa State University Pross, \$982), pp. $21 \div-32$.

Kreps, David M., and Robert Milson. "Sequental Equilibria," Econometrica (1982a), pp. $863-94$.

"Reputation and imperiect information," Joumal of Economic Theory, 27 (1982b), pp. 253-79.

Kydand, Fin E., and Prescott, Edward C. "Rules Father than Discretion: The inconsistency of Optirtal Plans," Joumat of Polftcal Economy (une 1977), pp. 473-91.

Lombra, Raymond E. "Monetary Policy: The Rhetoric Vorsus the Record, "in Monetany Refom and Economic Stabihy, Hearings before the Join Economic Commitee, 98th Cong., 2nd Sess. (U. S. Govenment Printing Ofice, May it and June 5,1984 , pp. $401-35$. 
, and Michael Moran. "solicy Advice and Policymaking at the Federal Reserve," Carnegie Rochester Conference Series on Public Policy (1980), pp. 9-68.

Lucas, Robert E., Jr. "Some Intemational Evidence on OutputInfiation Tradeoffs," American Economic Review (June 1973), pp. $326-35$.

Mayer, Thomas. "A Case Study of Federal Reserve Policymaking: Regulation Q in 1966," Joumal of Monetary Economics (September 1982), pp. 259-72.

McCallum, Bennett T. "Credibility and Monetary Policy," in Price Stability and Public Policy - A Symposium Sponsored by the Federal Reserve Bank of Kansas City, Jackson Hole. Wyoming (August 2 and 3, 1984).

Pierce, James L. "Making Reserve Targets Work," in Controlling Monetary Aggregates II, Federal Resene Bank of Boston Conference Series (1980), No. 23.
Rogoff, Kenneth. "The Optimal Degree of Commitment to an Intermediate Monetary Target," manuscript, University of Wisconsin (1985), forthcoming, Quarterly Joumal of Economics.

Taylor, John B. "Aggregate Dynamics and Staggered Contracts," Jounal of Political Economy (February 1980), pp. 1-23.

"Comments on 'Rules, Discretion and Reputation in a Model of Monetary Policy' by Barro and Gordon," Joumal of Monetary Economics (July 1983), pp. 123-25.

Weintraub, Robert E. "Congressional Supervision of Monetary Policy," Journal of Monetary Economics (April 1978), pp. 341-62.

Willet, Thomas D., and John McArthur. "Theories of Central Bank Behavior and Implications for Monetary Reform: A Constitutional Perspecive," paper presented at the meeting of the Western Economic Association, June 30-July 4, 1985, Anaheim, California.

Woolley, John T. Monetary Politics - The Federal Resenve and the Politics of Monetary Policy (Cambridge University Press, Cambridge, London, New York, 1984). 